Int. J. Electrochem. Sci., 12 (2017) $9180-9189$

\title{
Fabrication of a Graphene-Based Electrochemical Immunosensor for Ultrasensitive Analysis of Carcinoembryonic Antigens
}

\author{
Qingjun $\mathrm{Cui}^{*}$
}

Clinical Laboratory, Xintai People's Hospital, Xintai, Shandong, 271200 P.R. China

*E-mail: qingjuncuiXPHX@163.com

doi: $10.20964 / 2017.10 .77$

Received: 14 June 2017 / Accepted: 13 August 2017 / Published: 12 September 2017

\begin{abstract}
The clinical diagnosis and treatment evaluation of cancers require significantly sensitive determination of carcinoembryonic antigens (CEAs). This study proposed an electrochemical aptasensor for selective and sensitive determination of CEAs based on Pt/Au-diaminonaphthalene (DN)-graphene with the functions of electrocatalysts and nanocarriers. The capture of the developed bioconjugate onto the electrode surface occurred after the addition of CEAs via "sandwich" routes, which led to the appearance of an electrochemical response. An increase in the electrochemical response could be observed and ascribed to the desirable capacity, and peroxidase mimics the activity of dendritic $\mathrm{Pt} / \mathrm{Au} / \mathrm{DN}$-graphene, where the reduction of $\mathrm{H}_{2} \mathrm{O}_{2}$ added to the electrolyte cell was catalysed. Therefore, the sensitivity of the as-prepared aptasensor could be enhanced herein.
\end{abstract}

Keywords: Carcinoembryonic antigen; Aptamer; Graphene; Immunosensor; Au NPs; Pt NPs

\section{$\underline{\text { FULL TEXT }}$}

(C) 2017 The Authors. Published by ESG (www.electrochemsci.org). This article is an open access article distributed under the terms and conditions of the Creative Commons Attribution license (http://creativecommons.org/licenses/by/4.0/). 